\title{
ALGUNAS CUESTIONES SOBRE: «EL AGUA EN EL SURESTE PENINSU - LAR DURANTE ÉPOCA ROMANA. SU APROVECHAMIENTO PARA LA AGRICULTURA»
}

\author{
$M^{a}$ JUANA LÓPEZ MEDINA ${ }^{1}$ \\ Universidad de Almería
}

\begin{abstract}
Este trabajo es una reflexión sobre la importancia del aprovechamiento del agua para la actividad agrícola en el mundo romano, y en concreto en el sureste peninsular. Para ello se analiza tanto la documentación escrita como arqueológica, teniendo en cuenta que los datos que aporta esta última cada vez son mayores.

This paper shows the importance of water and the development of different items to take of it advantage for the farming activity in the Roman world, and in the particular case of the south-east the Iberian Peninsula. To get to that point we analyse the documental sources (written as well as archeological).
\end{abstract}

\section{INTRODUCCIÓN}

El trabajo aqui presentado sale a la luz como una reflexión de uno anterior, que fue expuesto como comunicación en el // Coloquio de Historia y Medio Físico: Agricultura y regadío en Al-Andalus, celebrado en Almería durante los días 9 y 10 de Junio de 1995, y en el cual participé. Este trabajo en concreto se titulaba «El agua en el sureste peninsular durante época romana. Su aprovechamiento para la agricultura", y tanto el debate que suscitó, como las deficiencias de su edición, es lo que me mueven a desarrollar estas líneas.

En cuanto a su edición, ésta ha sido llevada a cabo por los investigadores $L$. Cara Barrionuevo y A. Malpica Coello, y las Actas de dicho coloquio han sido publicadas por el Instituto de Estudios Almerienses y el Grupo de Investigación Toponimia, Historia y Arqueología del Reino de Granada de la Universidad de Granada, en Almería 1996. Las deficiencias de su edición se refieren en primer lugar al texto, que se puede consultar de las páginas 13 a 16 de dichas Actas. A éste le falta por publicar una parte importante. En segundo lugar estas deficiencias también se observan en el debate que suscitó, que en su transcripción ha sufrido ligeras variaciones, como por ejemplo la omisión de ciertas declaraciones.

Debido a ello me creo en el deber de volver a presentar el texto completo tal y como allí fue entregado, con sus planteamientos y sus errores. De esta manera pretendo subsanar las posibles malas interpretaciones que pueda crear en quien lea dicho trabajo, tanto de fondo, como de forma. Así por ejemplo, en cuanto a la forma, las notas aparecen variadas en su número por lo que no coinciden las referencias a la bibliografía, pues, incluso, buena parte de ésta ha desaparecido. De fondo ustedes mismos pueden apreciarlos. Por lo tanto, la primera parte de este trabajo consiste en la reproducción del texto original, colocando entre corchetes la parte omitida?

La segunda parte, es un comentario, tanto a mi propio texto como al debate que éste suscitó, planteando una serie de problemas que son frecuentes en nuestro mundo académico. En este sentido tengo que apuntar que sólo pretendí con este trabajo llamar la atención sobre la importancia del regadío en un medio árido o semi-árido. Éste, pues, se debería entender como una técnica, con un fin social, es decir, no sólo sirve para regar jardines y hortalizas (las plantas no son su fin único), sino prin-

\footnotetext{
${ }^{1}$ Becaria Postdoctoral de la Universidad de Almería. Departamento de Historia, Geografía e Historia del Arte, área de Historia Antigua.

2 El texto se ha mantenido original, salvo las notas y referencias bibliográficas que han debido ser adaptadas a las normas de publicación de esta revista.
} 
cipalmente para abastecer a los grupos humanos de una serie de productos, que sobre todo en ciertos medios necesitan de agua para su cultivo. Así pues estos productos, o bien sólo se pueden obtener mediante la utilización de esta técnica -son plantas de regadío-, o bien la irrigación se hace necesaria para su cultivo en determinadas zonas, más áridas -nos referimos a las consideradas plantas de secano-. En este último sentido, debemos tener en cuenta que por ejemplo en el sureste durante épocas de sequía se tiene que regar incluso hasta el trigo.

\section{$* * * \quad * * *$}

\section{TEXTO ORIGINAL: «EL AGUA EN EL SURES- TE PENINSULAR DURANTE ÉPOCA ROMA- NA. SU APROVECHAMIENTO PARA LA AGRICULTURA»}

\section{INTRODUCCIÓN}

El presente trabajo parte de la siguiente consideración: la importancia que el agua adquiere en un medio árido, muy parecido al actual, para los grupos humanos que en él habitan. $Y$ el período en el que nos vamos a centrar es la época romana, por lo tanto, en los precedentes de la agricultura de regadío andalusí. La importancia, anteriormente mencionada, se debe no solamente a que éste es un elemento indispensable para el consumo animal, y por lo tanto, de hombres y mujeres, sino también por su necesaria presencia en ciertas actividades que se realizaron en época romana como son la agricultura, la minería y las labores relacionadas con la pesca, como son las salazones de pescado.

Por la propia temática de Coloquio, la agricultura y el regadío en Al-Andalus, así como por cuestiones de espacio, el aspecto que aquí se va a tratar versa sobre el aprovechamiento de este agua [[[con respecto a una de las citadas actividades, la agricultura, que como bien sabemos es la base de toda economía antigua y, cómo no, del mundo romano. La transcendencia de esta actividad económica, se refleja en la propia consideración que tiene de ella la sociedad romana: la tenencia de tierras era considerada entre la clase superior, dirigente (ordo senatorial, ordo ecuestre y ordo decurional), como la principal fuente de rique$z a, o$ por lo menos de riqueza que ennoblece ${ }^{3}$.
Es por esto por lo que dicha clase estaba compuesta por grandes propietarios. La tierra era, pues, fuente de prestigio y de poder político en el mundo romano ${ }^{4}$.

Así pues, este trabajo es una síntesis en la que se han tenido en cuenta los dos tipos de fuentes más representativos en este aspecto, es decir, las fuentes escritas (textos literarios, textos jurídicos) y la arqueología.

\section{EL MEDIO FÍSICO}

Pero antes de examinar más detenidamente la relación existente entre el agua y la agricultura durante época romana en el sureste peninsular, creo que es necesario hacer una aproximación al medio físico sobre el cual estos grupos humanos actuaban. Es decir, vamos a intentar establecer una visión del paleoambiente en el sureste a raíz de los datos que provienen de estudios específicos en esta temática, aportados por las series polínicas, faunísticas, paleobotánicas y edafológicas de yacimientos de esta zona.

En este sentido la mayoría de los datos, referidos principalmente a la Prehistoria Reciente, apuntan a la existencia de un clima muy parecido al actual, es decir, un clima árido, aunque algo más húmedo, en el que la cobertura vegetal, bosques, y los recursos acuíferos eran más abundantes (los cauces fluviales serían más estables) (HERNANDO GONZALO, 1987a; 1987b, 171-200). Muestra de ello son los recursos forestales, principalmente bosques formados por encinas, que según las fuentes escritas del siglo pasado, así como los estu-

\footnotetext{
${ }^{3}$ Sobre este aspecto consultar: STE. CROIX, 1988, 140141; VEYNE, 1990, 36-38; GARNSEY y SALLER, 1990, 132; HOPKINS, 1981, 17.

${ }^{4} \mathrm{El}$ resto de actividades que podían generar riqueza, como son el comercio, el artesanado, estaban mal vistas en la sociedad romana, como muestran Cicerón (De Oratore, I. 234257; De Offic., I. 151, I. 92), Calistrato (Digesto, L. 2, 12). De este apartado hay que excluir el prestamismo, la minería, y quizás la pesca, pues se consideraban actividades ligadas a la tierra. El comercio, por lo tanto, era la peor vista de todas las actividades, y principalmente estaba realizado por extranjeros y por trabajadores de status inferior (como libertos y esclavos) como reflejan CARANDINI $(1979,114)$, VEYNE $(1992,67)$ y GARNSEY y SALLER $(1990,70$ y 143$)$. De ahí que un comerciante que se hubiera enriquecido, debía invertir su dinero en tierra para ennoblecerse. Un claro ejemplo de esto lo tenemos en la figura literaria de Trimalción (un estudio interesante sobre este personaje lo hace P. Veyne (1990, pp. 11-51), al que titula «Vida de Trimalción»).
} 
dios paleobotánicos, tuvieron una mayor extensión que en la actualidad ${ }^{5}$. Esta degradacióni del medio se produce a partir del segundo milenio a.C., cuando los grupos humanos inciden sobre él de forma significativa (RODRÍGUEZ ARIZA, 1991), y se intensificó probablemente durante la Antigüedad, a partir de época fenicio-púnica y durante época romana, y la Edad Media, por el aprovechamiento de esta masa forestal para las actividades mineras y agrícolas ${ }^{6}$. Desde el siglo XIX hasta la actualidad se ha llevado a cabo un incremento de dicha degradación, debido a una tala indiscriminada de estos bosques mediterráneos, para llevar a cabo labores mineras, aumentar las tierras de cultivo, etc. Este proceso continuo que tiene su inicio en el segundo milenio y que sigue actuando hasta nuestros días, ha provocado una fuerte erosión, con lo cual el aporte de materiales como limos, ha dado lugar a la colmatación de los deltas de los ríos, así como a la modificación de la línea de costa. Esta ha sufrido un avance, sobre todo allí donde se ha producido la mayor sedimentación de los materiales erosionados, es decir, en las desembocaduras de los ríos y en las zonas cercanas a éstas favorecidas por la acción de las corrientes marítimas que han transportado y depositado dichos sedimentos (HOFFMANN, 1988; ARTEAGA ET ALII, 1985, 117-122).

De esto podemos inferir que la sociedad de época romana en el sureste peninsular contaría con mayores recursos acuíferos, sobre todo de superficie, pero que estarían mediatizados por un clima parecido al actual, donde el régimen de lluvias no sería mucho más elevado que en el presente.

\section{AGUA Y AGRICULTURA}

Como ya hemos expuesto, pese a la mayor humedad, la aridez de este territorio, debido a la falta de lluvias, junto con las propias necesidades de los grupos humanos, hacía indispensable la captación de aguas, tanto para el consumo propio como para las actividades económicas a las que antes hemos hecho mención. Así por ejemplo, el agua era un elemento indispensable para labores mineras, como el lavado de mineral (ej.: Fuente de Castala, donde se han hallado escoriales vinculados a esta labor $\left.^{7}\right)$. También era una de las condiciones básicas para la ubicación de una factoría de salazones, pues la existencia de abundante agua dulce era necesaria para limpiar el pescado, preparar la salmuera y limpiar la instala- ción (PONSICH y TARRADELL, 1956, 102; JIMÉNEZ CONTRERAS, 1986, 20-34; CHIC GARCÍA, 1994, 185-187); de ahí que éstas se suelan asentar cerca de la desembocadura de los ríos, como muestran las balsas de salazón halladas en la desembocadura del río Adra y en la del río Almanzora, que han sido puestas en relación con las antiguas ciudades de Abdera y Baria respectivamente ${ }^{8}$.

La importancia del aprovechamiento del agua se puede ver en la misma estructura del poblamiento, cuyos asentamientos se ubican en las márgenes de los ríos y ramblas, así como en las cercanías de las fuentes. Reflejo de esto es que la mayor concentración de poblamiento sigue los cauces de los ríos de esta zona (Adra, Andarax-Nacimiento y Almanzora), donde se hallan tanto los caudales de agua más estables, como los terrenos de cultivo más fértiles (los aluviales), según nos muestran las prospecciones que se están realizando desde la década pasada en distintas áreas, como Zona de Adra, Sierra de Gádor, Valle del Andarax, Pasillo de Fiñana, Depresión de Vera, Alto Almanzora y Comarca de los Vélez ${ }^{9}$.

A grandes rasgos la implantación agrícola de época romana está bastante desarro-

\footnotetext{
${ }^{5}$ Autores del siglo pasado: MADOZ (1845-1850, 125) y SANTOYO $(1869,11)$. Estudios paleobotánicos: MARISCAL (1991a, 394-399; 1991b, 726-734; 1992, 141-149; 1993, 5864).

${ }^{6}$ En la importancia de las tareas agrícolas con respecto al aumento de la erosión incide el investigador RANDSBORG (1991, 29-20): la tala de bosques, particularmente en regiones relativamente áridas, reduce los niveles de humedad y dispara la erosión, sobre todo en aquellas tierras que se han dejado de explotar. Según él, este aspecto tiene bastante importancia en el Mediterráneo, pues la historia política y social ha dado lugar a importantes fluctuaciones en el nivel de la actividad agrícola.
}

${ }^{7}$ CARA BARRIONUEVO Y RODRÍGUEZ LÓPEZ $(1987,86)$.

${ }^{8}$ Sobre las balsas de salazón de Abdera: FERNÁNDEZ MiRANDA y CABALLERO ZOREDA (1975, 153 y ss.); SUÁREZ MÁRQUEZ ET ALII (1986, 18-19); PONSICH (1988). Sobre Baria: SIRET (1908, 10-11); PONSICH y TARRADELL (1965, 82); PONSICH (1988, 175-176).

9 1) Zona de Adra: CARA BARRIONUEVO y RODRÍGUEZ LÓPEZ (1989, 49-58). 2) S. Gádor: CARA BARRIONUEVO y RODRÍGUEZ LÓPEZ (1987, 84-86). 3) Valle del Andarax: CARA BARRIONUEVO y CARRILERO MILLÁN (1985, 6366); CARA BARRIONUEVO y RODRÍGUEZ LÓPEZ (1986, 58-61). 4) Pasillo de Fiñana: ADROHER AUROUX ET ALII (1987, 77-80); LÓPEZ GODOY ET ALII $(1987,73-76)$; BUZÓN CALDERÓN ET AL// (1988, 9-13). 5) Depresión de Vera: CAMALICH MASSIEU ET ALI/ (1987, 33-36); QUINTERO ET AL/I $(1990,59-63)$. 6) Alto Almanzora: En esta zona actualmente el Grupo de Investigación ULISES está llevando a cabo un proyecto. 7) Comarca de los Vélez: MARTÍNEZ LÓPEZ y MUÑOZ MUÑOZ (1985, 55-62; 1986, 79-83; 1987, 167-169). 
llada durante el Alto Imperio, a partir de la mitad del siglo I d.C., como muestra el incremento de yacimientos relacionados con construcciones rurales (de pequeña o mayor entidad) que se produce a partir de esta fecha. Estos asentamientos parece que se mantienen hasta la denominada "crisis del siglo III", a partir de la cual los restos indican una paulatina concentración de la propiedad, articulándose el territorio en asentamientos de mayor entidad o villae, con la consecuente desaparición de parte de los altoimperiales. Esta situación de época bajoimperial, en líneas generales, parece ser que pervive durante la Antigüedad Tardía hasta la conquista musulmana ${ }^{10}$. Este esquema parte del análisis de los datos suministrados por las prospecciones de superficie de la zona estudiada, por lo que la práctica de excavaciones arqueológicas son necesarias para confirmar o variar estas hipótesis de trabajo.

Como ya se ha dicho antes la agricultura es el sector económico preponderante; y su producción se dedicaba principalmente al autoconsumo y al mercado local, según se puede inferir de las evidencias obtenidas]]] por las prospecciones arqueológicas que muestran la proliferación de pequeños asentamientos altoimperiales, y la posterior concentración del poblamiento en villae de carácter autárquico. Ésta se basaría en el complemento entre los cultivos de regadío y de secano.

De los cultivos de secano cabría destacar el de los cereales, y sobre todo, el del trigo, cuyo cultivo según P. Sáez $(1987,214)$, debió estar generalizado en toda la Bética, y al ser la base alimenticia de la Antigüedad, se debió cultivar en toda clase de tierras siempre que tuvieran unas condiciones mínimas de calidad, siendo principalmente su uso doméstico. En relación a este cultivo estaría el hallazgo de muelas de mano y piedras de molino en numerosos yacimientos de la zona estudiada (Ej.: Villavieja -Berja-, Turaniana -Bajos de Roquetas de Mar-, Murgi-Ciavieja, El Ejido-, Cjo. Cadimar -Turre-, Macián -Vélez Blanco-, etc. $)^{11}$.

Durante esta época, como ya hemos dicho, se va a producir el aprovechamiento de agua para la agricultura, y, por lo tanto, la práctica de cultivos de regadío. Dos hechos contribuyen a reafirmarnos la existencia de estos cultivos: por un lado, la arqueología, que cada vez con mayor profusión nos va mostrando restos de instalaciones relacionadas con la captación, transporte y almacenamiento de agua destinada a la agricultura, y por otro, las fuen- tes escritas, literarias, que nos hablan de la existencia de sistemas hidráulicos y productos de regadío para el consumo humano, y jurídicas, de la regulación municipal del abastecimiento del agua con este fin. Pasemos a examinar detenidamente cada uno de estos apartados.

Es bien sabido, que los romanos utilizaron técnicas de captación, transporte y almacenamiento de agua en relación con el consumo humano, de lo que hay notables ejemplos en la Península Ibérica (acueducto de Segovia, acueducto de Mérida), que servían para abastecer de este preciado líquido a los habitantes de los municipios (FERNÁNDEZ CASADO, 1972; 1983; WHITE, 1984, 157-173), tanto para su consumo individual como para su utilización en baños públicos o termas ${ }^{12}$. Ejemplos de esta técnica, aunque de menores proporciones en relación con el traslado y almacenamiento de agua para el abastecimiento de una comunidad existen también en el sureste, como es el caso de la atarjea romana que posiblemente trasladara agua desde el Marchal de Araoz hasta el municipio romano de Urci (El Chuche, Benahadux) (SÁNCHEZ LEÓN, 1978, 186) y el aljibe del Castillo de Abla en relación con el municipio de Alba (GIL ALBARRACíN, 1983a, 96-99).

Pero esta técnica también se aplicó a la agricultura dando lugar a un sistema de regadíos. Muestra de este último aspecto es la existencia de construcciones de cierta envergadura, acueductos, que generalmente llevaban el agua hacia villae de bastante importancia, de los cuales tenemos tres posibles ejemplos de época romana en nuestra zona de estudio: 1) el acueducto sobre la rambla de Julbena, del cual quedan dos columnas de mampostería, que llevaría el agua al pago de Negite (Berja), donde habría una villa de bastante entidad como prueba el hallazgo de un mosaico, inscripciones y restos de enterramientos (SÁNCHEZ LEÓN, 1978, 185-186; TAPIA GARRIDO, 1989, 40); 2) el acueducto de Carcauz formado por tres tramos que transportaría el agua desde un nacimiento situado en la rambla del

\footnotetext{
${ }^{10}$ Sobre estos yacimientos consultar la bibliografía de la nota 9 .

"Sobre este punto consultar la bibliografía de la nota 9 .

${ }^{12}$ Existen referencias de la existencia de termas en los municipios romanos de Tagiliy de Murgi, sufragadas por dos evergetas Voconia Avita (IRAL 48) y L. Aemilius Daphnus (IRAL 43) respectivamente.
} 
mismo nombre hasta la denominada balsa del "Molinero", para una vez ahí regar las tierras de la villa situada en Casablanca (GIL ALBARRACÍN, 1983a, 125-162; TOVAR, 1989, 144), aunque su datación no es precisa porque su utilización, prácticamente hasta nuestros días, ha provocado numerosas obras de mantenimiento; 3) el acueducto de Albanchez, datado por GIL ALBARRACÍN (1983b, 1-15) en época imperial, se conoce con el nombre de "Los Arcos" y sus restos se hallan aproximadamente a dos kilómetros de esta localidad, en la ladera del Maimón. Sólo mediante un trabajo de campo, que incluya el análisis y comparación de las técnicas constructivas, se podría llevar a cabo un estudio más pormenorizado de estos restos hidráulicos, siendo posible así fijar su datación, que plantea problemas a la investigación actual.

Existen además otra serie de construcciones de menor entidad a los que se denominan sistemas de «pequeña hidráulica» asociados a villae, que aparecen aislados en zonas de montaña aprovechando fuentes marginales, y que están compuestos normalmente por una mina y una balsa de acumulación; este sistema lo han estudiado L. Cara Barrionuevo y J.M. Rodríguez López a través de los restos hallados en sus prospecciones de la Sierra de Gádor y el término municipal de Adra, en asentamientos como La Curibaila, La Catalana, La Parra, todos ellos en Adra, Cjo. del Tartel en Felix, etc. (CARA BARRIONUEVO y RODRÍGUEZ LÓPEZ, 1989, 55-57; RODRÍGUEZ LÓPEZ y CARA BARRIONUEVO, 1989, 447-448).

Estos sistemas deberían estar acompañados de acequias o surcos practicados en la tierra para facilitar la distribución del agua a las parcelas destinadas al regadío. Estas conducciones serían muy frágiles, incluso podrían estar realizadas directamente sobre la tierra, por lo que es muy difícil poder documentarlas a través de la arqueología.

Con respecto a las fuentes literarias, éstas nos hacen referencia a distintos aspectos dentro del cultivo de regadío, como pueden ser las labores de recuperación de tierras, donde cobraría especial importancia el abono animal o stercoratio, y posteriormente las de preparación, con actividades como la aratio $^{13}$ (para lo que se utilizaría el arado romano). Además son significativas las referencias a maquinaria hidráulica que servía para la captación de estas aguas, entre las que se pueden citar técnicas como la rota, o noria, y la ciconia denominada por Plinio como tolleno (es un balancín que se apoya sobre un poste vertica! y que tiene en uno de sus extremos un recipiente para recoger agua y en otro un contrapeso), etc. ${ }^{14}$ Así estos sistemas de regadío aprovecharían el agua para el cultivo de distintas variedades frutales y hortalizas (ej.: coles, espárragos, alcachofas, lechugas, ciruelos, etc.), como ponen de manifiesto Plinio (N.H. XV, 42; XIX, 152), Columela (De r.r., VIII, 17, 15; X, 185, 192) y San Isidoro (Etymologiae XVII, 10, 11). Algunos de estos frutos se podían secar, lo que hacía más fácil su conservación, tal y como ocurre en la actualidad con los higos (Columela, De r.r., VIII, 17, 15; XII, 15, 5). Estas fuentes son una documentación indirecta para la zona estudiada, puesto que no se refieren en particular a ésta, sino a un territorio más amplio como es la Bética.

Otro dato más nos viene a refrendar el uso del agua, y su importancia para las comunidades aquí asentadas en relación con la agricultura. Nos estamos refiriendo a la regulación por parte del municipio de la captación, transporte, almacenamiento y posterior redistribución de estas aguas para riego a los habitantes de las ciudades romanas, como es el caso de la colonia de Urso, como pone de manifiesto la lex Ursonensis ${ }^{15}$. En los capítulos XCVIIII y CIIII de dicha ley se establece que las obras de construcción y reparación de canales debían ser competencia de los duunviros, máximo cargo administrativo dentro de un municipium romano. De nuevo estamos ante una fuente indirecta sobre la utilización de esta agua, que quizás se podría aplicar a los municipios romanos que se incluyen en este área Abdera (Adra), Murgi (El Ejido), Urci (El Chuche), Alba (Abla), Tagili (Tíjola) y Baria (Villaricos, Cuevas de Almanzora), lo que no estaría de más si tenemos en cuenta la importancia que ésta debía tener.

Por consiguiente, se tienen datos cada vez más evidentes, para llegar a la conclusión de que el regadío, en esta zona fue anterior a

\footnotetext{
${ }^{13}$ Isidoro, Ethymologiae XVII, 2, 3; XVII, 2, 2 (SALVADOR VENTURA, 1989, 407-418)

14 Ibidem, XX, 15, 1-2.

${ }^{15}$ Lex Coloniae Genitiva Iuliae, XCVIIII, CIIII, en estos capítulos se reglamenta el uso de las aguas de la colonia, haciendo referencia a las de riego y a los canales que delimitaban los campos, tal y como ya lo han puesto de manifiesto autores como SÁNCHEZ LEÓN $(1978,185)$ o GONZÁLEZ FERNÁNDEZ (1990, 33-34, 35-36).
} 
la presencia musulmana, aunque hay que incidir en la necesidad de realizar nuevas investigaciones, sobre todo, a través de excavaciones. En esta valoración no entramos en la cuantificación de dicho sistema agrícola, pues, como sabemos, su mayor implantación se producirá a partir de época musulmana, además los restos que poseemos siguen siendo escasos para valorar su implantación generalizada. Por consiguiente lo que queremos resaltar es que en el sureste peninsular antes de la conquista musulmana y su asentamiento en estas nuestras tierras, ya existía una tradición de aprovechamiento del agua con fines agrícolas. Aspecto ya puesto de relieve en otros trabajos como el de F. Salvador Ventura $(1989,407-418)$ y los de L. Cara Barrionuevo y J.M. Rodríguez López (1989; RODRÍGUEZ LÓPEZ y CARA BARRIONUEVO, 1989, 443-463) entre otros.

\section{COMENTARIO}

Este trabajo fue introducido en dicho Coloquio dentro de la primera mesa de debate que tenía el título de «ESTUDIOS DE FUENTES DOCUMENTALES», y como bien afirmó el moderador de dicha mesa, Tomás Quesada, éste versaba sobre "la utilización del agua en el medio rural en el Sudeste peninsular durante la época romana, desde la doble perspectiva de las fuentes escritas y arqueológicas. Esencialmente, después de hacer un estudio paleoclimático en el que llega a la conclusión de que el clima sería muy parecido al actual aunque algo más humedo, al haber una mayor cobertura forestal-, constata la existencia de obras hidráulicas en el medio rural’ (CARA BARRIONUEVO y MALPICA CUELLO, 1996, 109). Por consiguiente, el que haya leído este comentario echará en falta en la publicación de las Actas la parte donde se tratan los aspectos referentes al medio físico durante época romana, por lo tanto el estudio paleoclimático.

Me pareció muy estimulante que éste fuera uno de los trabajos sobre los que se discutió, precisamente por no estar vinculado directamente al mundo medieval, que era el tema central de dicho Coloquio. Eso ha sido para mí un motivo de reflexión muy interesente durante todo este tiempo, y se ha acentuado ahora que no ha aparecido en dichas Actas gran parte del "debate-diálogo» que se produjo. $Y$ es que aún sigue existiendo una controvertida dis- cusión sobre el origen del regadio en la Península Ibérica, si musulmán, si romano. En este sentido es sintomático destacar la opinión de un investigador de los sistemas hidráulicos andalusies, como es Miquel Barceló. Para él: "La discusión, perversamente ideológica, sobre los "orígenes" romanos o árabes de los sistemas hidráulicos de Valencia, Murcia y Orihuela, principalmente, ha conseguido paralizar la investigación arqueológica sobre el hidraulismo andalusí que, quizá, hubiera dado sentido a un debate de este tipo o, simplemente, lo hubiera hecho imposible. La única investigación relevante, exceptuando, ocasionalmente, algunos geógrafos e ingenieros, sobre el hidraulismo andalusi, la han producido historiadores y arqueólogos exteriores a la historiografía española. Toda la obstinada y crispada discusión sobre los "orígenes" ha transcurrido sin que nadie supiera con precisión cómo era el hidraulismo andalusí, y con ideas muy rudimentarias sobre la función social y objetivos del hidraulismo romano (...). Por consiguiente, es aconsejable aplazar el debate hasta que se haya caracterizado adecuadamente la estructura técnica, la función social y la difusión y desarrollo histórico del hidraulismo, o sea, de la agricultura andalusí, de los específicos procesos de trabajo campesino" (BARCELÓ, 1988, 243).

En este mismo sentido también se manifiestan KIRCHNER y NAVARRO (1994, 195), al comparar la discusión entre el origen romano y musulmán del regadío, con el origen oriental o magrebí de la hidráulica andalusí. Para ellas "discutir, pues, sobre el origen oriental o magrebi de la hidráulica andalusí puede ser tan estéril como discutir sobre los orígenes romanos o islámicos de los riegos de al-Andalus cuando, apenas se sabe nada de la hidráulica romana, que no sea urbana, es decir, de conducción de aguas a núcleos urbanos».

Por una parte estoy de acuerdo con la postura desarrollada por Miquel Barceló en el estudio anteriormente referido, y es la importacia de estudiar las técnicas en cada una de las épocas, aunque élisólo se refiere a época musulmana. Quizás esto está motivado por la falta de estudios sobre las técnicas de regadío en época romana, puesto que la mayor parte de la investigación está empezando ahora. El motivo principal es que la arqueología clásica se ha "especializado» en el estudio de las grandes construcciones, de ahí que la mayoría de las excavaciones se hayan realizado en restos vinculados a núcleos urbanos, y den- 
tro de los asentamientos rurales, a las zonas residenciales de las villae. Éstas son generalmente las más espectaculares, puesto que suelen aparecer restos ornamentales con dependencias lujosamente decoradas con estucos pintados, mosaicos, etc., como destaca el estudio de AGUILAR SÁENZ (1991, 261-279) sobre las dependencias de funcionalidad agrícola en las villae peninsulares. Actualmente cada vez está cobrando más importancia el análisis de las partes dedicadas a las funciones económicas de la villa, es decir, a la pars rustica, y ello repercute directamente en el estudio de los restos hidráulicos. Por consiguiente, aún faltan datos tan importantes como son las cronologías en gran parte de los casos, 10 que nos puede permitir poner todas estas estructuras en relación. Sin embargo, esto -la falta de datos- no debe ser un motivo para no intentar profundizar en esta cuestión, sino la base sobre la cual seguir trabajando.

Por lo tanto, pese a estas deficiencias no creo que el debate deba ser aplazado, puesto que es mediante éste como se puede producir un mejor conocimiento sobre las sociedades que estudiamos. Así pues, este debate debe ser paralelo al desarrollo de otras líneas de investigación versadas sobre la época romana, como son el estudio morfológico de las construcciones relacionadas con la captación, conducción y almacenamiento de agua en relación a la actividad agrícola, perímetros de riego, etc. Además estos mismos autores llaman la atención sobre la existencia de algunas soluciones técnicas para la construcción de espacios irrigados previas a la islamización (KICHNER y NAVARRO, 1994, 159).

En relación a esto, hoy en día está bien claro el importante papel que adquirió el regadío en la Península lbérica bajo la dominación musulmana, como lo están y han estado demostrando un importante número de investigadores. Por consiguiente, no pretendemos con este estudio hacer coincidir los sistemas hidráulicos andalusies con estructuras romanas, sino solamente llamar la atención sobre la existencia de cultivos irrigados en época romana, por lo que el papel del regadío romano en la economía de estos grupos humanos no se debe menospreciar. Estamos pues de acuerdo con la afirmación sobre este debate de GONZÁLEZ VILLAESCUSA (1996, 347), "no negamos la importancia de su correcta dilucidación con argumentos contundentes pues la investigación histórica debe permitir ordenar cronológicamente los acontecimientos sociales con el fin de que este "relato" adquiera significación y puedan ser interpretados a la luz de ese orden. Creemos que esos argumentos de peso pueden surgir del análisis morfológico, a falta de proyectos de largo alcance que aporten las pruebas arqueológicas positivas necesarias".

Pero además, y paralelamente, cada vez son más numerosos los restos a nivel arqueológico que nos vienen a demostrar que esta técnica agrícola tiene un amplio desarrollo en otras sociedades, como la romana. ¿Por qué nos debe extrañar esta utilización, si los romanos podríamos considerarlos como «ingenieros del agua"? En relación a esto nos hablan sus sistemas de captación, conducción y almacenaje, así como los de drenaje en sus ciudades, la construcción de termas, fuentes, piscinas, los sistemas de desagüe de las minas, etc. Además debemos tener en cuenta que el desarrollo de sistemas de captación y almacenamiento de aguas ya se había iniciado en comunidades prehistóricas, por lo menos en el sureste peninsular. Así se conocen estos sistemas en poblados prehistóricos desde el neolítico-cobre, como la conducción de Ciavieja, la conducción de Los Millares, las galerías del yacimiento argárico de Gatas, el aljibe del Peñón de la Reina, e, incluso, algunas han sido relacionadas con el regadío como el canal del poblado argárico del Cerro de la Virgen de Orce $^{16}$. ¿Y por no ser utilizadas para una producción mercantil se deben menospreciar?

En principio podríamos afirmar que el regadío durante época romana tuvo un papel especial en amplias áreas donde la falta de lluvias requería la captación de aguas no sólo para el consumo humano, sino también para la práctica de actividades como la agrícola. En este sentido son significativos los restos del Pasillo Sirio-Palestino y del norte de África, pero también y más cercanos a nosotros los de la Península Ibérica.

Así MALISSARD $(1996,154-155)$ al estudiar las conducciones de agua hace referencia a embalses destinados a actividades agrícolas, es decir, a la irrigación, poniéndolos en relación con la necesidad de algunas comuni-

\footnotetext{
${ }_{16}$ Sobre la conducción de Ciavieja: CARRILERO MILLÁN y SUÁREZ MÁRQUEZ (1989-1991, 113-115). Sobre las galerías del yacimiento argárico de Gatas: CHAPMAN (1991). Sobre el aljibe del Peñón de la Reina: MARTÍNEZ PADILLA y BOTELLA $(1980,243)$. Sobre el canal del Cerro de la Virgen de Orce: SCHÜLE $(1967,115-117 ;$ 1986, 216).
} 
dades de garantizar la regularidad del suministro, principalmente en las regiones áridas. Se trata de cisternas descubiertas que se llenaban de modo esporádico con las lluvias y las avenidas de ríos y fuentes. Algunos de estos embalses conocidos por el momento son los de más envergadura y capacidad, y entre ellos destaca el de Habarqua, cerca de Palmira, o el de Homs (Emesa) ambos en Siria. Entre sus funciones destacan: desvío de pequeñas corrientes fluviales, irrigación, retención de aluviones destinados a fertilizar las zonas desérticas, etc. Como el mismo autor afirma "la existencia de tales obras, costosas y de prestigio, no se justificaba verdaderamente sino en las regiones donde los ríos podían secarse al cesar las lluvias". El primero de los mencionados, la presa de Habarqua se eleva hasta 20 $\mathrm{m}$. y corta un valle de $365 \mathrm{~m}$. de anchura. En cuanto al segundo, el embalse de Homs, tenía dos mil metros de largo y una capacidad aproximada de noventa millones de metros cúbicos.

Pero, además contamos con otras obras menos monumentales, que de igual manera nos llaman la atención sobre la importancia dada al control del agua en regiones áridas, del Norte de África. Así se conocen construcciones de tierra, de hasta siete metros de altura y en ocasiones incluso ochocientos metros de longitud en Tripolitania, que permitían irrigar los campos adyacentes (WHITE, 1986, 168-169; MALISSARD, 1996, 154).

En la Península Ibérica los restos están dispersos por prácticamente toda su geografía. Así por ejemplo en Lusitania, donde se ha incidido bastante en el estudio de restos hidráulicos, GORGES (1992-1993, 270-272) ofrece una larga lista donde detalla las construcciones que existen relacionadas con el agua, entre las que nombra algunas que presentan una relación directa con la práctica del regadío, como son Las Tomas, El Peral, Esparragalero, Cjo. de Araya, Charca de Valverde, Muro dos Mouros, etc. Además en la actual provincia de Toledo se han localizado varias presas relacionadas directamente con asentamientos rurales romanos (OREJAS y SÁNCHEZ PALENCIA, 1989, 45-67). Entre éstas quizás destacan los restos de sistemas de canalización y presas de agua en la villa de Peñaflor en el territorio de Lacimurga, junto al Guadiana (AGUILAR SÁENZ ET ALII, 1992-1993, 120), y al acueducto de la villa de São Cucufate (GORGES, 1992-1993, 261-262). En la Tarraconense, por ejemplo, se ha estudiado la presa de Sarral en Tarragona, que se ha relacionado con una villa importante situada a aproximadamente un kilómetro (BELTRÁN DE HEREDIA BERCERO ET ALII, 1989, 311-333). De la misma forma se han documentado estructuras relacionadas con el regadío en la Bética, junto al río Guadalquivir, como es el caso de las estructuras aparecidas en la Campiña de Córdoba, realizadas todas en opus caementicium y revestidas de opus incertum (LACORT NAVARRO, 1989, 391-393).

Restos de estas construcciones también se han hallado en zonas cercanas a la nuestra y con parecidas condiciones climáticas, como por ejemplo en la región murciana, donde existen testimonios de acueductos relacionados con la irrigación como el de Casa de los Cobos en Jumilla, Albatana en Albacete, Carche junto a Jumilla, o presas en el Guadalentín y en la Rambla del Moro (LÓPEZ DE LA PLAZA, 1991, 62-64)

En cuanto al sureste, aparte de los restos que han sido relacionados en el trabajo original han salido a la luz otros durante estos últimos años, como el acueducto del Pago de Escuchagranos, del cual se pueden observar tres arcos; éste no conserva restos del specus o canal de conducción, y su cronología ha sido establecida durante época romana, puesto que no existen yacimientos de otra etapa posterior cerca de él; en cuanto a su función según sus investigadores no está clara, por lo que o bien podría abastecer de agua a la villa cercana, o bien podría formar parte de un sistema de regadío (ADROHER AUROUX y POCIÑA LÓPEZ, 1996). Entre estos restos también podemos incluir la conducción hidráulica del corte 3 de Cabecico de Parra de Almizaraque, aunque su uso no ha sido precisado (LÓPEZ CASTRO ET ALII, 1988, 10).

La constatación de estos restos en distintas áreas de la Península Ibérica nos conduce a una nueva pregunta. ¿Era el regadío una práctica más generalizada de lo que cabría esperar durante época romana? Así nos lo vendrían a demostrar varios aspectos que tienen como base los restos arqueológicos y los datos aportados por el análisis de las fuentes escritas:

En primer lugar, debemos tener presente la aparición de restos de construcciones relacionadas con el agua y la actividad agrícola en lugares de mayor pluviosidad, es decir, en zonas más humedas que el actual sureste. Esto nos podría demostrar que el clima no fue el factor determinante para la construcción al menos de ciertas estructuras relacionadas con el agua. 
Por otro lado, las referencias que existen en los agrónomos latinos sobre la propia necesidad del regadío, o la maquinaria hidráulica. Así Columela $(1,2,4)$ se manifiesta sobre la importancia del regadío al afirmar: "También será el caso un nacimiento de agua de donde se saquen acequias que rieguen los prados, los huertos y los saucedales de la villa».

Como ya hemos mencionado, también reafirma la utilización del regadío como práctica en cierta medida generalizada la regulación por parte de la colonia de Urso de la captación, conducción y almacenamiento de aguas para riego, como se desprende de la lex Ursonensis (caps. XCVIIII y CIIII).

En este sentido también podemos contar con el cultivo de plantas de regadío, es decir, de distintas variedades frutales y hortalizas (ejs.: coles, espárragos, lechugas, ciruelos, perales, etc.). El mismo Catón hacía referencia a las buenas propiedades de las coles, que es una planta de regadío. En este sentido es necesaria la aplicación de técnicas de recuperación del registro arqueológico (como flotación, lavado, tamizado fino, etc.) para el estudio de carbones, semillas y otros restos vegetales en yacimientos del sureste peninsular con niveles de época romana (ejs.: Cerro de Montecristo -Abdera-, Ciavieja -Murgi- o Villaricos -Baria-), así como en otros yacimientos de la Península Ibérica, mediante los cuales se podrá constatar qué familias de plantas se cultivaban.

Para nosotros la existencia de estas plantas son una prueba más de la práctica de esta técnica, lo importante sería pues constatar la existencia en estos yacimientos de plantas de regadío en general, no de una determinada especie. Las plantas que se consumen son productos culturales, desde el momento en el que los grupos humanos deciden cuales forman parte de su régimen alimentario. Así, la existencia del regadío en ciertas zonas es anterior al cultivo de algunas plantas. Un ejemplo muy significativo puede ser el cultivo del tomate, como todos sabemos es una planta de regadío que llega del continente americano después de la conquista, por consiguiente su cultivo en la Península lbérica es posterior a la introducción del regadío. Por lo tanto, discrepamos de la afirmación realizada en el Coloquio por BARCELÓ (CARA BARRIONUEVO y MALPICA CUELLO, 1996, 337-338), que en las Actas aparece de la siguiente manera: "El agua es sólo un instrumento que permite el cultivo de unas plantas determinadas que antes no exis- tían en esta zona árabes y beréberes transportan la técnica al agua, no porque el agua en si sea buena, no porque la hidráulica en sí sea un signo de una agricultura superior, que no lo es, sino para servir de soporte a una agricultura de plantas, cosechas y calendarios agrícolas nuevos y diferentes. En este sentido, la intervención de Juana López Medina es correcta y a la vez incorrecta. Efectivamente, en época romana habia riego. Se regaban ciertas plantas, pero no espinacas, ni berenjenas, ni alcachofas. Estamos hablando de un elenco de plantas que viaja de las zonas monzónicas hasta aquí y que exigen el agua. Las técnicas hidráulicas no llegan como signo de una mejor agricultura, sino simplemente como soporte. Debiamos haber empezado por estudiar las plantas, situándolas en el centro de la investigación, y no las técnicas de riego». Esta intervención es por sí un tanto ambigua, porque ino podríamos deducir de ella que lo que se plantea es que la técnica del regadío procede también de esas zonas monzónicas, si se defiende que dichas plantas procedian de zonas monzónicas y la técnica hidráulica es el soporte de dichas plantas?

Con este trabajo no se intenta, tal y como dije con anterioridad, cuantificar el papel del regadío en época romana puesto que por ahora no hay suficientes datos, sino afirmar que debió tener una importancia económica y social, puesto que permitía cubrir parte de las necesidades de alimentación de las personas que aquí vivieron. Por lo tanto, la importancia no es tanto de las plantas, al ser éstas productos culturales, como del significado del regadío para el sistema económico y las personas que lo controlan. Lo que deberíamos analizar es el papel que tuvo la irrigación para aquellos grupos humanos que lo practicaban -el porqué, el cómo, el dónde, el cuándo-.

\section{BIBLIOGRAFÍA}

ADROHER AUROUX, A.M. y POCIÑA LÓPEZ, C., 1996: "Pago de Escuchagranos: un yacimiento tardorromano en ia Provincia de Almería", Pyrenae, 27, 227-250.

ADROHER AUROUX, A.M. ET ALII, 1987: «Prospección superficial en Pasillo de Fiñana, Sierra de Baza y Sierra Nevada", Anuario Arqueológico de Andalucia., vol. II, 77-80.

AGUILAR SÁENZ, A. 1991: «Dependencias con funcionalidad agrícola en las villas romanas de la Península Ibérica», Gerion. Homenaje al Dr. Michel Ponsich, Anejos III, 261-279.

AGUILAR SÁENZ, A. ET ALII, 1992-1993: «La ciudad antigua de Lacimurga y su entorno rural», Studia Historica. $H^{a}$ Antigua, $X-X I, 109-130$. 
ARTEAGA, O. ET ALII, 1985: «Investigaciones geológicas y arqueológicas sobre los cambios de la línea de costa en el litoral de la Andalucía Mediterránea. Informe preliminar (1985)», Anuario Arqueológico de Andalucía, vol. Il, 117-122.

BARCELÓ, M. 1988: «La arqueología extensiva y el estudio de la creación del espacio rural", en BARCELÓ, M. et alii: Arqueología medieval. En las afueras del «medievalismo", Barcelona, 195-274.

BELTRÁN DE HEREDIA BERCERO, J. ET ALII, 1989: «La presa de Sarral (Tarragona): primeros resultados del estudio arqueológico, histórico y sedimentológico", El agua en las zonas áridas: Arqueología e Historia, vol. I. Actas del l Coloquio de Historia y Medio Físico, Almería 14-15-16 de diciembre 1989, Almería, 311-333.

BUZÓN CALDERÓN, F. ET ALII, 1988: «Informe de las prospecciones arqueológicas superficiales en el pasillo de Fiñana (Almería). Campaña 1988», Anuario Arqueológico de Andalucia, vol. II, 9-13.

CAMALICH MASSIEU, M.D. ET ALII, 1987: «Prospección arqueológica superficial en la Cuenca del Bajo Almanzora (Almería). Informe provisional de la campaña de 1987», Anuario Arqueológico de Andalucía, vol. II, 33-36.

CARA BARRIONUEVO, L. y CARRILERO MILLÁN, M. 1985: «Prospección arqueológica superficial del estuario del Andarax y piedemonte de la Sierra de Gádor (Almería), 1985», Anuario Arqueológico de Andalucía, vol. II, 6366.

CARA BARRIONUEVO, L. Y MALPICA CUELLO, A. (Eds.) 1996, Actas del // Coloquio de Historia y Medio Físico: Agricultura y regadio en Al-Andalus, Almería 9 y 10 de Junio de 1995, Almería.

CARA BARRIONUEVO, L. y RODRÍGUEZ LÓPEZ, J.M. 1986: «Prospección arqueológica superficial del Valle Medio del río Andarax (Almería)", Anuario Arqueológico de Andalucia, vol. II, 58-61.

CARA BARRIONUEVO, L. y RODRÍGUEZ LÓPEZ, J.M. 1987 : "Memoria sobre la prospección arqueológica superficial de la Sierra de Gádor (Almería)", Anuario Arqueológico de Andalucía, vol. II, 84-86.

CARA BARRIONUEVO, L. y RODRÍGUEZLÓPEZ, J.M. 1989: "Agricultura y poblamiento en Adra (Almería). Primeros resultados de una prospección arqueológica", Anuario Arqueológico de Andalucia, vol. III, 49-58.

CARANDINI, A. 1979: L'Anatomia della Scimmia. La Formazione economica della Società prima del Capitale, Torino.

CARRILERO MILLÁN, M. y SUÁREZ MÁRQUEZ, A. 19891991: “Ciavieja (El Ejido, Almería): Resultados obtenidos en las campañas de 1985 y 1986. El poblado de la Edad del Cobre», Cuadernos de Prehistoria de la Universidad de Granada, 14-15, 109-136.

CHAPMAN, R. 1991: La formación de las sociedades complejas. El sureste de la Península lbérica en el marco del Mediterráneo Occidental, Barcelona.

CHIC GARCÍA, G. 1994: «La proyección económica de la Bética en el Imperio Romano (Época Altoimperial), Actas del II Congreso de Historia de Andalucia, Córdoba 1991, Córdoba, 173-199.

FERNÁNDEZ CASADO, C. 1972: Acueductos romanos en España, Madrid.

FERNÁNDEZ CASADO, C. 1983: Ingeniería hidráulica romana, Madrid.

FERNÁNDEZ-MIRANDA FERNÁNDEZ, M. y CABALLERO ZOREDA, L. 1975: Abdera. Excavaciones en el Cerro de Montecristo (Adra, Almería), Madrid.

GARNSEY, P. y SALLER, R. 1990: El Imperio Romano. Economía, sociedad y cultura, Barcelona (London 1987).

GIL ALBARRACÍN, A. 1983a: Construcciones romanas de Almería, Almería.
GIL ALBARRACÍN, A. 1983b: «El acueducto de Albanchez y el Valle del Almanzora en época romana", ROEL, 4, 1-15.

GONZÁLEZ FERNÁNDEZ, J. 1990: Bronces jurídicos romanos de Andalucia, Sevilla.

GONZÁLEZ VILLAESCUSA, R. 1996: «Paisaje agrario, regadío y parcelarios en la Huerta de Valencia. Nuevos planteamientos desde el análisis morfológico", en CARA BARRIONUEVO, L. y MALPICA CUELLO, A. (Eds.): Actas del // Coloquio de Historia y Medio Físico: Agricultura y regadio en Al-Andalus, Almería 9 y 10 de Junio de 1995, Almería, 343-360.

GORGES, J.-G. 1992-1993: «La place de l'eau dans les villas luso-romaines: de l'hydraulique domestique à I'hydraulique rurale", Studia Historica. $H^{a}$ Antigua, X$X I, 253-272$.

HERNANDO GONZALO, A. 1987a: Evolución interna y factores ambientales en la interpretación del Calcolítico del sureste de la Península lbérica. Una revisión critica, Tesis doctoral, Universidad Complutense, Madrid.

HERNANDO GONZALO, A. 1987b: «¿Evolución cultural diferencial del Calcolítico entre las zonas áridas y húmedas del sureste español?", Trabajos de Prehistoria, 44, 171-200.

HOFFMANN, G. 1988: "Holozänstratigraphie und Küstenlinienverlagerung an der Andalusischen Mittelmeerküste", Berichte aus dem Fachbereich Geowissenschaften der Universität Bremen, 2, Bremen.

HOPKINS, K. 1981: Conquistadores y Esclavos, Barcelona (Cambridge, 1978).

JIMÉNEZ CONTRERAS, S. 1986: «La industria del pescado en la Antigüedad», Revista de Arqueología, 68, 2034.

KICHNER, H. y NAVARRO, C. 1994: «Objetivos, métodos y práctica de la Arqueología hidráulica», Arqueología y territorio medieval, I, Jaén, 159-182.

LACORT NAVARRO, P.J. 1989: "Obras hidráulicas e implantación romana en la Campiña de Córdoba», El agua en las zonas áridas: Arqueología e Historia, vol. I. Actas del I Coloquio de Historia y Medio Físico, Almería 14-15-16 de diciembre 1989, Almería, 359404.

LÁZARO PÉREZ, R. 1980: Inscripciones romanas de Almería, Almería (=IRAL).

LÓPEZ CASTRO, J.L. ET AL/I, 1988: "Memoria de la excavación de urgencia en Cabecico de Parra de Almizaraque (Cuevas de Almanzora, Almería)», Anuario Arqueológico de Andalucía, vol. III, 7-11.

LÓPEZ GODOY, N. ET ALII, 1987: “Prospección en el Pasillo de Fiñana (Almería)", Anuario Arqueológico de Andalucia, vol. II, 73-80.

LÓPEZ DE LA PLAZA, G. 1991: “Murcia», Historia de los regadios en España (... a.C.-1931), Madrid, 56-64.

MADOZ, P. 1845-1850: Diccionario geográfico-estadístico-histórico de España y sus posesiones de UItramar, Madrid.

MALISSARD, A. 1996: La cultura del agua en la Roma antigua. Los romanos y el agua, Barcelona (Paris 1994).

MARISCAL, B. 1991a: "Características ambientales durante el Holoceno en las Pilas de Mojácar, Almería. Análisis polínico en la Cuenca del río Aguas", Boletín Geológico y Minero, 102-3, 394-399.

MARISCAL, B. 1991b: “Características climáticas y ambientales durante el Holoceno en Almizaraque. Análisis polínico de los sedimentos fluviales de Villaricos (Almería)", Boletín Geológico y Minero, 102-5, 726734. 
MARISCAL, B. 1992: «Variación de la vegetación durante ol subboreal. Análisis polinico en Cabezo de Brujas, Almizaraque (Almería), Revista Española de Micropaleontología, XXIV-1, 141-149.

MARISCAL, B. 1993: “Fluctuación climática y actividad antrópica durante el Subboreal. Estudio polínico de Almizaraque, Herrerías (Cuevas de Almanzora), Almería", Boletín Geológico y Minero, 104-1, 58-64.

MARTÍNEZ LÓPEZ, C. y MUÑOZ MUÑOZ, F.A. 1985: «Prospecciones arqueológicas de superficie de los yacimientos ibéricos y romanos de la vega de Vélez Blanco (Almería), 1985", Anuario Arqueológico de Andalucía, vol. II, 55-62.

MARTÍNEZ LÓPEZ, C. y MUÑOZ MUÑOZ, F.A. 1986: «Memoria sobre las prospecciones arqueológicas de superficie de los yacimientos ibéricos y romanos de la Comarca de los Vélez (Almería). Fase II: Hoya del Marqués-Cueva Ambrosio-Río Alcaide", Anuario Arqueológico de Andalucia, vol. II, 79-83.

MARTÍNEZ LÓPEZ, C. y MUÑOZ MUÑOZ, F.A. 1987: «Memoria sobre las prospecciones arqueológicas de superficie de los yacimientos ibéricos y romanos de la Comarca de los Vélez. Fase IIl: Los altiplanos de Topares", Anuario Arqueológico de Andalucía, vol. II, 167-169.

MARTÍNEZ PADILLA, C. y BOTELLA, M. 1980: El Peñón de la Reina (Alboloduy, Almería), Madrid.

OREJAS SACO DEL VALLE, A. y SÁNCHEZ PALENCIA, F.J. 1989: «Obras hidráulicas romanas y explotación del territorio en la provincia de Toledo", El agua en las zonas áridas: Arqueología e Historia, vol. I. Actas del 1 Coloquio de Historia y Medio Físico, Almería 14-1516 de diciembre 1989, Almería, 45-67.

PONSICH, M. 1988: Aceite de oliva y salazones de pescado. Factores geo-económicos de Bética-Tingitania, Madrid.

PONSICH, M. y TARRADELL, M. 1956: Garum et industries Antiques de Sailason dans la Méditerranée Occidentale, Paris.

QUINTERO, P. ET ALII, 1990: «Prospección arqueológico superficial en la cuenca del Bajo Almanzora (Almería). Informe provisional de la campaña 1990", Anuario Arqueológico de Andalucia, vol. II, 59-63.

RANDSBORG, K. 1991: The First Millennium A.D. in Europe and the Mediterranean. An archaeological essay, Cambridge.

RODRÍGUEZ ARIZA, M.O. 1991: “Human-plant relationships during the Copper and Bronze Ages in the Baza and Guadix Basins (Granada, Spain)", Les charbons de bois, les anciens écosystèmes et le rôle de l'homme, Colloque organisé à Montpellier du 10 au 13 septembre 1991 par II Vernet, Bull. Soc.Bot.Fr., 139, Act.bot. (2/3/4), 451-464.

RODRÍGUEZ LÓPEZ, J.M. y CARA BARRIONUEVO, L. 1989: «Aproximación al conocimiento de la historia agrícola de la Alpujarra Oriental (Almería). Épocas antigua y medieval" en El agua en las zonas áridas: Arqueología e Historia, vol. I: Actas del I Coloquio de Historia y Medio Físico, Almería 14-15-16 de diciembre de 1989, Almería, 443-463.

SAÉZ FERNÁNDEZ, P. 1987: Agricultura romana de la Bética. I, Sevilla.

STE. CROIX, G.E.M. 1988: La lucha de clases en el mundo griego antiguo, Barcelona.

SALVADOR VENTURA, F. 1989: «La agricultura de regadio durante la Antigüedad Tardía en el sur de la Península lbérica", El agua en las zonas áridas: Arqueología e Historia. Actas del I Coloquio de Historia y Medio Físico, Almería 14-15-16 de diciembre de 1989, vol. l, Almería, 407-418.

SÁNCHEZ LEÓN, M.L. 1978: Economía de la Hispania Meridional durante la dinastía de los Antoninos, Salamanca.

SANTOYO, E. 1869: Crónica de la provincia de Almería, Madrid.

SCHÜLE, W. 1967: «El poblado del bronce antiguo en el Cerro de la Virgen de Orce (Granada) y su acequia de regadío", IX Congreso Nacional de Arqueología (Valladolid 1965), Valladolid, 113-121.

SCHÜLE, W. 1986: «El Cerro de la Virgen de la Cabeza, Orce (Granada): Consideraciones sobre su marco ecológico y cultural», Homenaje a Luis Siret (19341984), Madrid, 208-220.

SIRET, L. 1908: Villaricos y Herrerias. Antigüedades púnicas, romanas, visigodas y árabes, Madrid.

SUÁREZ MÁRQUEZ, A. ET ALII, 1986: "Memoria de la excavación de urgencia efectuada en el cerro de Montecristo. Adra (Almería)», Anuario Arqueológico de Andalucia, vol. III, 16-19.

TAPIA GARRIDO, J.A. 1989: Historia de la Baja Alpujarra, Almería (1965).

TOVAR, A. 1989: Iberische Landeskunde, Band 3: Tarraconensis, Baden-Baden.

VEYNE, P. 1990: La sociedad romana, Madrid.

VEYNE, P. 1992: «El Imperio Romano", en ARIÉS, P. y DUBY, G. (Dirs.): Historia de la vida privada. l.: Imperio Romano y Antigüedad Tardía, Madrid.

WHITE, K.D. 1986: Greek and Roman Technology, London (1984). 